\title{
Incivility in the workplace: A study of nursing staff in the Military Health System
}

\author{
Colleen Spiri , Meredith Brantley, Jason McGuire \\ Daniel K. Inouye Graduate School of Nursing, Uniformed Services University of the Health Sciences, Bethesda, United States
}

Received: September 5, 2016

DOI: $10.5430 /$ jnep.v7n3p40
Accepted: October 13, $2016 \quad$ Online Published: October 27, 2016

URL: http://dx.doi.org/10.5430/jnep.v7n3p40

\begin{abstract}
Incivility in the workplace is associated with decreased quality of performance. In a healthcare setting, decreased performance diminishes the opportunity for excellence in patient care and introduces potential threats to patient safety and wellbeing. Affected individuals and those who witness the most severe form of workplace incivility, including bullying, are likely to experience negative psychosocial consequences such as depression, substance abuse, and suicide. The degree to which different forms of incivility persist in healthcare settings is unclear and as a result, the sources of workplace incivility and its effects on nursing staff and their patients are also not well established. This study explored the prevalence of eight different forms of incivility toward nursing staff, profiles of the main offenders of incivility, and the impact of each behavior on patient care from the perspective of a sample of nursing staff affiliated with one Military Health System (MHS) hospital. Condescending language (56\%) and impatience with questions (58\%) were most commonly reported as occurring sometimes or often in the workplace. Nursing peers were cited as the most common source of incivility (33\%). Negative impacts of workplace incivility on patient care included breakdown in communication, often involving nursing staff avoiding uncivil coworkers. Findings suggest the importance of implementing interventions designed to reduce incivility in military healthcare settings.
\end{abstract}

Key Words: Workplace bullying, Workplace incivility, Healthcare disruptive behaviors

\section{INTRODUCTION}

Experiences of incivility in the workplace have been studied since the 1980s, prompted by the establishment of a clinic in Sweden for individuals traumatized in the workplace. ${ }^{[1]}$ Workplace bullying, one of the most severe forms of incivility, has been associated with poor mental and physical health among victims, including diminished cognitive functioning, chronic stress, high blood pressure, and coronary heart disease. ${ }^{[2]}$ Individuals experiencing bullying in the workplace have also been found to be at increased risk for depression, prolonged duress stress disorder, alcohol abuse, post-traumatic stress disorder (PTSD), and suicide. ${ }^{[2]}$ A pub- lished definition of workplace bullying distinguishes why it is considered one of the most severe forms of incivility, "Bullying constitutes evolving and often escalating hostile workplace relationships rather than discrete and disconnected events and is associated with repetition (frequency), duration (over a period of time), and patterning (of a variety of behaviors involved) as its most salient features". ${ }^{[3]}$

The impact of incivility in the United States' healthcare setting first surfaced in 2008 when the Joint Commission (JC) published a call to eliminate employee behaviors that undermine patient safety. ${ }^{[4]}$ Intimidating and disruptive behaviors were linked to medical errors, adverse health outcomes,

\footnotetext{
*Correspondence: Colleen Spiri; Email: Colleen.spiri@gmail.com; Address: Daniel K. Inouye Graduate School of Nursing, Uniformed Services University of the Health Sciences, Bethesda, United States.
} 
increased medical expenditures, and staff turnover. Intimidating and disruptive behaviors were identified in the JC's sentinel alert as "overt actions such as verbal outbursts and physical threats, as well as passive activities such as refusing to perform assigned tasks or quietly exhibiting uncooperative attitudes during routine activities... reluctance or refusal to answer questions, return phone calls or pages; condescending language or voice intonation; and impatience with questions". ${ }^{[4]}$ Investigation of incivility in the Military Health System (MHS) is important because the MHS adheres to the JC standards and there have been no published studies exploring incivility, inclusive of the disruptive behaviors named in this sentinel alert, in the MHS.

The military's success in providing excellent patient care to active duty and family members, retirees, and veterans relies heavily on the health of the nurse workforce. The nurse workforce in Military Health System (MHS) hospitals includes both civilian (contract and General Service [GS]) and military staff. The GS staff is stationary and work on one particular unit for long periods of time, often through retirement. Contract employees are more transient and offer diverse background experiences to their contracting hospital. In contrast, military staff is assigned to units based on the needs of the military and their experience designators which are assigned by the military. Military staff generally rotates to other units, specialties, or commands every one to three years, all while they are often required to travel unexpectedly for training and deployment. The military staff leadership on inpatient units change every one to three years. A military officer's career is highly dependent on creating measurable change in a leadership role in order to achieve advancement. A better understanding of incivility in the military healthcare setting will inform programs to ensure excellence by locally improving patient and employee healthcare environments.

This descriptive study aimed to explore incivility in the MHS. Specifically, the purpose of this study was to measure the prevalence of incivility experienced by nursing staff, characterize the main offenders, and investigate the impact of each behavior on patient care from the perspective of a sample of nursing staff affiliated with one MHS hospital.

\section{MethodS}

\subsection{Sample population and study design}

The sample was drawn from nurses working in one MHS hospital in 2015. The sample population was comprised of inpatient unit nursing staff regardless of military status or professional licensing (e.g., registered nurses [RNs], nursing assistants). The diversity of the staff spanned those in military service, GS, and contract nursing personnel. Military staff included representatives from the United States armed

Published by Sciedu Press forces branches of the Navy, Army, and Air Force. The study population also included both licensed and unlicensed nursing staff, including RNs, licensed practice nurses (LPNs), nursing aids and technicians, military medics, and hospital corpsmen.

\subsection{Definitions}

The term incivility was selected for this study because the Joint Commission identified civility as a system value responsible for improving safety in health care settings. ${ }^{[5]}$ The term incivility encompasses a broad range of terms used in the study of negative behaviors in the workplace (see Table 1). Incivility included "any negative behavior that demonstrates a lack of regard for other workers". ${ }^{[6]}$ Subtle incivility was defined by condescending language, impatience, refusal to answer or respond, or statements similar to "just give me what I ordered". ${ }^{[7,8]}$ Explicit incivility was defined by verbal abuse and threatening body language. The most severe form of incivility measured was physical abuse.

\subsection{Instrumentation}

The survey used to assess workplace incivility was a modified version of the Institute for Safe Medication Practices' (ISMP) Survey on Workplace Intimidation. The ISMP is a patient safety organization (PSO) federally certified to provide healthcare organizations with protection and confidentiality to submit patient safety data. ${ }^{7,8]}$ The ISMP's survey was chosen for this study for its relevance in the healthcare environment and for its history in revealing the details of hostile work environments that erode professional communication. ${ }^{[7,8]}$ At the time this study was conducted there were no survey tools available to the principle investigator for measuring incivility among nurses specifically, which necessitated modification of an available survey. The modifications were limited to changing the references to offenders from medication prescribers to prescribers and co-workers in general. The existing incivility literature, some of which was summarized above, informed the appropriateness of the survey, particularly regarding the behaviors measured. Due to the modification of the survey, there is no valid psychometric data available.

Six-hundred hospital staff were invited via email to participate in the survey by rating the frequency of eight uncivil behaviors, ranging from subtle affronts to physical violence experienced in the workplace throughout the previous year. A subsequent set of questions queried participants about their perspectives on the impact of these behaviors on patient safety. Another set of survey items captured respondent opinion of organizational resources available for managing incivility. A final set of questions sought to discern the most 
common offenders of incivility experienced in the workplace. February 2015. The survey was voluntary, and the submisSeveral of these questions referred to behaviors of practitioners, including both medical doctors and nurse practitioners. The study was introduced at one Senior Nurse Executive meeting and two follow-up reminder emails were sent to the 600 email addresses over a six week period, from Januarysion of the survey was considered consent. The electronic format of data collection was anonymous and respondents provided no identifying information. The hospital's Institutional Review Board (IRB) for the protection of human subjects approved this study.

Table 1. Incivility Terms and Definitions

\begin{tabular}{|c|c|}
\hline Terms & Definitions \\
\hline Incivility & $\begin{array}{l}\text { Using demeaning or disparaging language, gestures or behaviors. Gossip and slander. Intimidation. Sabotaging. } \\
\text { Bullying. Offensive written communication. Hate-ism (Rankism, Racism, ageism, sexism) }{ }^{[18]} \text {. }\end{array}$ \\
\hline Bullying & $\begin{array}{l}\text { A situation where one or several individuals persistently over a period of time perceive themselves to be on the } \\
\text { receiving end of negative actions from one or several persons, in a situation where the target of bullying has } \\
\text { difficulty in defending him or herself against these actions }{ }^{[3]} \text {. }\end{array}$ \\
\hline Negative Acts & An inventory of 21 acts associated with bullying ${ }^{[3]}$. \\
\hline Negative Behaviors & Potentially intimidating behaviors ${ }^{[7]}$. \\
\hline Horizontal Hostility & $\begin{array}{l}\text { Overt or covert lateral violence including name calling, negative body language, intimidation, gossip, } \\
\text { fault-finding, blaming, refusing to help someone, withholding information, unfair/inappropriate assignments, } \\
\text { isolation, and sabotage }^{[12]} \text {. }\end{array}$ \\
\hline Disruptive Behavior & Intimidating and unprofessional behaviors that undermine patient safety ${ }^{[4]}$. \\
\hline Workplace Violence & 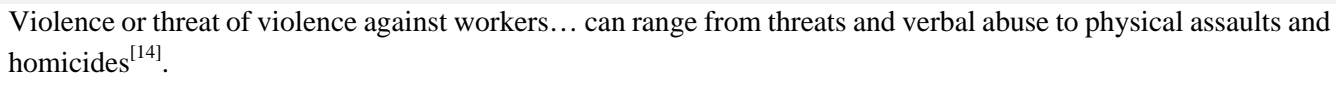 \\
\hline Relational Aggression & Covert aggression or bullying $^{[19]}$. \\
\hline $\begin{array}{l}\text { Lateral } \\
\text { violence/Horizontal } \\
\text { Violence }\end{array}$ & $\begin{array}{l}\text { Demeaning and downgrading of others with unkind words and cruel acts often causing a wide variety of negative } \\
\text { effects }{ }^{[20]} \text {. }\end{array}$ \\
\hline
\end{tabular}

\subsection{Analysis}

This study analyzed the survey data using descriptive statistics, including frequency of demographic and work-related characteristics of the sample. Prevalence of different experiences of incivility in the workplace, offenders as perceived by respondents impact on patient safety, and staff satisfaction were also assessed. Among 600 nurses offered an opportunity to participate, 155 (26\%) completed the survey (see Table 2).

\section{RESULTS}

\subsection{Nurse workforce experiences of incivility in the workplace}

Approximately $88 \%$ of respondents reported encountering some sort of incivility in the workplace over the past year. Among the more subtle forms, more than $80 \%$ reported condescending language or impatience with questions. Seventyeight percent of respondents reported experiencing reluctance or refusal to answer questions, return calls, or return pages from coworkers; $60 \%$ experienced communication in the form of "just give what I/the attending ordered". More than half of the respondents reported experiencing two of the three more explicit negative behaviors surveyed: $52 \%$ experienced strong verbal abuse and $55 \%$ experienced negative or threatening body language (see Figure 1). Physical abuse was reported by three respondents.

\subsection{Offenders as perceived by respondents}

Nurse work force peers were reported as the most common offenders by $33 \%$ of respondents. Practitioners, which included physicians and nurse practitioners, were identified as the most common offenders by $26 \%$ of respondents. Less than $10 \%$ of respondents identified nursing administrators or patient/patient family as the most common offenders. The employment type identified as the most common offender was the active duty military officer $(37 \%)$ and the GS employees $(27 \%)$.

\subsection{Impact on patient safety}

Among the patient safety questions, $55 \%$ of respondents avoided interacting with the offending practitioner/colleague by seeking help from other colleagues while $47 \%$ did not seek help and ensured the safety of the order themselves. Approximately $38 \%$ reported asking another colleague to talk to the practitioner/colleague to clarify an order. Thirty-one percent of respondents reported that they assumed the order was correct rather than interact with a particular prescriber/colleague. Thirty-seven percent of respondents reported feeling pres- 
sure to accept an order or dispense/administer a medication which they addressed questions about patient care. Four redespite safety concerns (see Table 3). About $31 \%$ of re- spondents report being involved in a medication error where spondents reported that intimidation has altered the way in intimidation played a role.

Table 2. Demographics of respondents $(\mathrm{N}=155)$

\begin{tabular}{|c|c|c|c|c|c|c|}
\hline Items & & $\mathbf{N}$ & $\%$ & Military status & $\mathbf{N}$ & $\%$ \\
\hline \multirow[t]{3}{*}{ Gender } & & & & Military & 101 & $65 \%$ \\
\hline & Female & 116 & $75 \%$ & Civilian-GS & 46 & $30 \%$ \\
\hline & Male & 39 & $25 \%$ & Civilian-contractor & 8 & $5 \%$ \\
\hline \multirow[t]{7}{*}{ Age, years } & & & & Rank & & \\
\hline & $<24$ & 27 & $17 \%$ & O1-O3 & 67 & $43 \%$ \\
\hline & $25-34$ & 60 & $39 \%$ & O4 and above & 7 & $5 \%$ \\
\hline & $35-44$ & 21 & $14 \%$ & E1-E3 & 17 & $11 \%$ \\
\hline & $45-54$ & 27 & $17 \%$ & E4-E5 & 8 & $5 \%$ \\
\hline & $55-64$ & 17 & $11 \%$ & E6 and above & 2 & $1 \%$ \\
\hline & $65-74$ & 3 & $2 \%$ & N/A (civilian) & 54 & $35 \%$ \\
\hline \multicolumn{4}{|c|}{ Time been working at hospital } & Nursing type & & \\
\hline & $\leq 2$ & 82 & $53 \%$ & Bedside & 139 & $90 \%$ \\
\hline & 3 to 5 & 51 & $33 \%$ & Middle manager & 14 & $9 \%$ \\
\hline & 5 to 10 & 10 & $6 \%$ & Senior leadership & 2 & $1 \%$ \\
\hline & 10 to 20 & 9 & $6 \%$ & & & \\
\hline & $\geq 20$ & 3 & $2 \%$ & & & \\
\hline \multicolumn{4}{|c|}{ Unit/department affiliation } & Nursing role & & \\
\hline & Adult ICU & 28 & $18 \%$ & Corpsman & 25 & $16 \%$ \\
\hline & Mother/Infant & 10 & $6 \%$ & Licensed Practical Nurse & 10 & $6 \%$ \\
\hline & Medical surgical ward & 69 & $45 \%$ & Medic & 9 & $6 \%$ \\
\hline & PACU & 1 & $1 \%$ & Registered Nurse & 111 & $72 \%$ \\
\hline & PICU/NICU & 23 & $15 \%$ & & & \\
\hline & Pediatric Ward & 8 & $5 \%$ & & & \\
\hline & Telemetry & 16 & $10 \%$ & & & \\
\hline
\end{tabular}

Note. PICU: pediatric intensive care unit; NICU: neonatal intensive care unit; PACU: post anesthesia care unit.

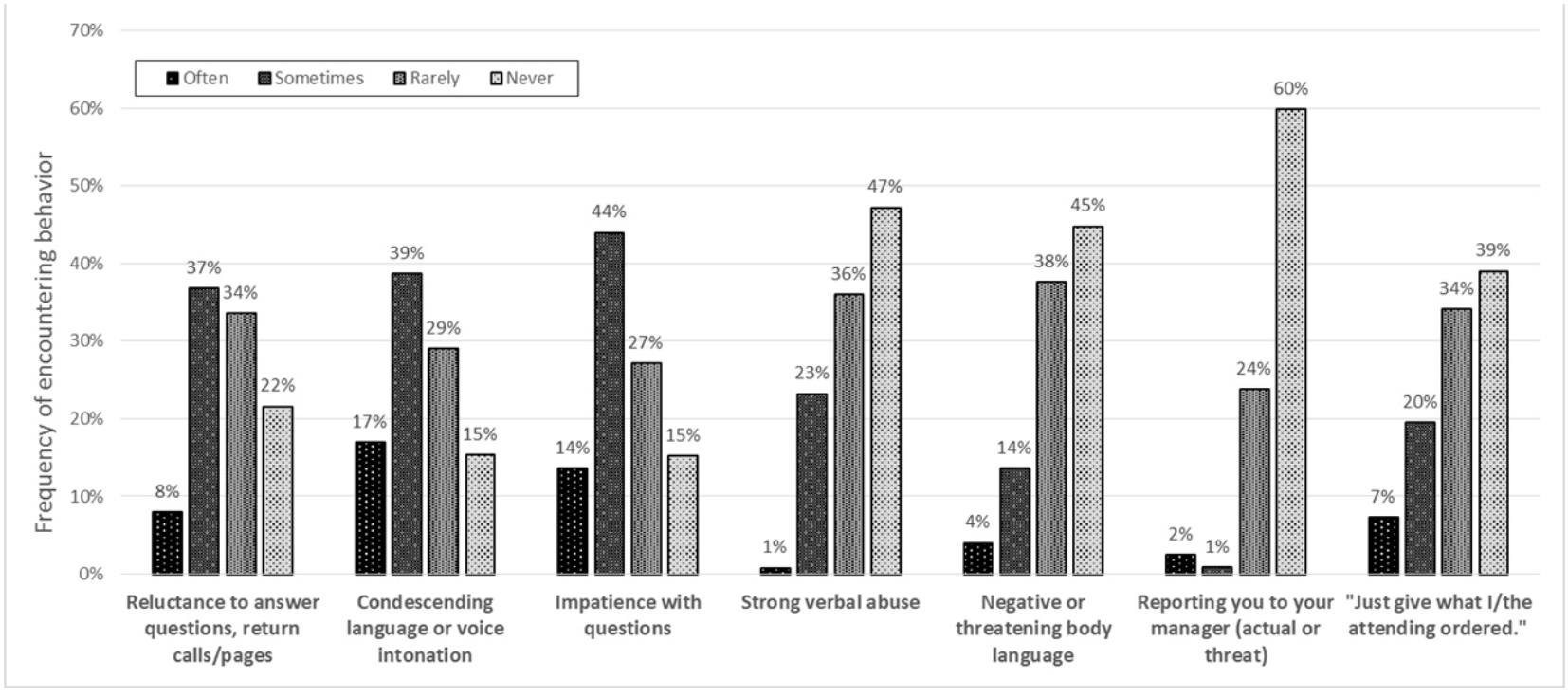

Figure 1. Experiences of incivility in the nursing workforce $(\mathrm{N}=155)$ 
Table 3. Frequency of experiencing effects of incivility among nurses in a military hospital

\begin{tabular}{|c|c|c|c|c|c|c|c|c|c|}
\hline \multirow{2}{*}{ Item } & \multicolumn{2}{|c|}{ Often } & \multicolumn{2}{|c|}{ Sometimes } & \multicolumn{2}{|c|}{ Rarely } & \multicolumn{2}{|c|}{ Never } & \\
\hline & n & $\%$ & n & $\%$ & n & $\%$ & $\mathbf{n}$ & $\%$ & \\
\hline $\begin{array}{l}\text { Despite concern (even if vague), I've assumed that an } \\
\text { order is correct and safe rather than interact with a } \\
\text { particular prescriber/colleague }(n=118)\end{array}$ & 1 & $1 \%$ & 14 & $12 \%$ & 30 & $25 \%$ & 73 & $62 \%$ & 118 \\
\hline $\begin{array}{l}\text { Despite concern (even if vague), I've assumed that an } \\
\text { order is correct and safe because of the stellar repuation } \\
\text { of the prescriber/colleague ( } \mathrm{n}=118 \text { ) }\end{array}$ & 3 & $3 \%$ & 9 & $8 \%$ & 25 & $21 \%$ & 81 & $69 \%$ & 118 \\
\hline $\begin{array}{l}\text { I've asked colleagues to help me interpret an order or } \\
\text { validate its safety so that I do not have to interact with a } \\
\text { particular prescriber/colleague }(\mathrm{n}=118)\end{array}$ & 12 & $10 \%$ & 29 & $25 \%$ & 24 & $20 \%$ & 53 & $45 \%$ & 118 \\
\hline $\begin{array}{l}\text { I've refrained from contacting a prescriber/colleague and } \\
\text { attempted to clarify the safety of an order by researching } \\
\text { the topic myself }(n=117)\end{array}$ & 3 & $3 \%$ & 23 & $20 \%$ & 29 & $25 \%$ & 62 & $53 \%$ & 117 \\
\hline $\begin{array}{l}\text { I've asked another professional to talk to the } \\
\text { prescriber/colleague (or other professional) about the } \\
\text { safety of an order if it involves a particularly intimidating } \\
\text { person }(n=120 \text { ) }\end{array}$ & 3 & $3 \%$ & 17 & $14 \%$ & 26 & $22 \%$ & 74 & $62 \%$ & 120 \\
\hline $\begin{array}{l}\text { I’ve asked/suggested/allowed a prescriber/colleague to } \\
\text { give a medication despite concerns (even if vague) about } \\
\text { its safety }(n=116)\end{array}$ & 0 & $0 \%$ & 7 & $6 \%$ & 22 & $19 \%$ & 87 & $75 \%$ & 116 \\
\hline $\begin{array}{l}\text { I've felt pressured to accept an order, dispense a product, } \\
\text { or administer a medication despite concerns (even if } \\
\text { vague) about its safety }(\mathrm{n}=116)\end{array}$ & 3 & $3 \%$ & 10 & $9 \%$ & 30 & $26 \%$ & 73 & $63 \%$ & 116 \\
\hline
\end{tabular}

\subsection{Staff satisfaction}

Forty-seven percent of respondents reported that their organization did not deal effectively with intimidating behavior. Thirty-one percent reported no clear defined process for handling disagreements about patient safety and $40 \%$ reported the process for handling clinical disagreements does not allow them to bypass the practitioner or their supervisor if necessary. Seventy-eight percent reported that their organization/manager would support them if they reported negative or intimidating behavior.

\section{Discussion}

This descriptive study endeavored to explore workplace incivility in an MHS facility, as perceived by the nurse workforce. Findings suggest that incivility in the workplace is a problem at this hospital within the MHS and it is similar to results published on the topic conducted in civilian hospitals. ${ }^{[3,9]}$ Hospitals that have had success in implementing interventions, such as the Veteran Affairs' CREW program, ${ }^{[10]}$ may provide options for hospitals in the MHS to effectively address this issue.

\subsection{Incivility}

The results indicated incivility is perceived as occurring at this MHS facility. The literature suggested that uncivil work environments are associated with negative psychosocial consequences for employees ${ }^{[2]}$ and decreased quality of performance for healthcare organizations. ${ }^{[4]}$ The collective suggestion is to identify interventions to promote a civil workplace, while periodically assessing the perception of incivility to guide further intervention in the pursuit of a safe environment for employees and patients.

\subsection{Offenders}

Hospitals are fundamentally hierarchical. Physicians hold significant power, which can facilitate a context for power abuse. ${ }^{[9]}$ The most recent American studies on power abuse are from the 1980s and 1990s. Surveys of medical students and RNs show harassment and verbal abuse to be a common phenomenon. American surveys from the 1980s showed physicians to be the main offenders. A similar Norwegian study from 1998 showed other RNs to be the main offenders, which is consistent with a 2001 Danish study. ${ }^{[9]}$

The data from this study is consistent with the more recent studies out of Norway and Denmark, ${ }^{[9]}$ showing nursing peers to be the most common offenders. This finding is relevant because a previous study revealed nurse to nurse aggression to be the most distressing type when compared with aggression nurses encounter from physicians, patients, and patient families. ${ }^{[11]}$ The majority of incivility reported in this 
study is subtle however; the fact that peers are the main perpetrators gives it the potential to be the most impactful source of stress at work on a daily basis. The results of this study indicate that practitioners were only $5 \%$ behind nurse colleagues as the most common type of offender. Bartholomew's oppression theory suggests nurses "eat their young" because they are oppressed by the control of practitioners, administrators and patients. Nurses take their frustrations out on each other laterally because they cannot go upwards with them. ${ }^{[12]}$

\subsection{Patient safety}

The study results identified communication barriers, which are clearly detrimental to patient safety, ${ }^{[7,8]}$ that respondents attributed to uncivil behavior from coworkers. Workplace culture was an area of research identified for future exploration by several authors in the literature on incivility current at the time of this study. ${ }^{[10,12]}$ Uncivil workplace cultures present barriers to the helpfulness of change initiatives for patient care and quality improvement. ${ }^{[10]}$ Perceived incivility, possibly as a result of an uncivil work environment culture, in this study led respondents to seek clarification on prescribed patient care from sources other than the practitioner or to proceed with care they felt was unsafe. Addressing the breakdown in communication with change initiatives may not be effective if an underlying uncivil culture is present. More exploration is needed to identify if culture is the root cause of the incivility perceived by respondents in this facility, however identifying it as the root cause may provide guidance for selecting the most effective interventions.

\subsection{Organizational support}

Results indicated that nearly half of the respondents perceived their organization did not deal effectively with incivility. This finding is not unusual because there is no federal standard requiring protection. The Society for Human Resource Management (SHRM) pointed out that targets of incivility are not covered under anti-discrimination law unless they are part of a protected class. ${ }^{[13]}$ The results highlighted the group of individuals at this MHS facility who perceive incivility in the workplace, but are not part of a protected class, and indicate the organization either lacks or does not promote a system to address incivility in the workplace.

Agencies monitoring workplace environments highlighted the prevalence of incivility in the healthcare setting, which had historically been entrenched in silent acceptance, ${ }^{[6]}$ and led efforts to define standards for actionable behaviors. The Occupational Safety and Health Administration's (OSHA) workplace violence webpage named health care professionals as a group at high risk for workplace violence. ${ }^{[14]}$ The National Institute for Occupational Safety and Health (NIOSH)

Published by Sciedu Press published statistics revealing about 24,000 health care setting workplace assaults between 2010 and 2013. ${ }^{[15]}$ Since the results of these investigations have become public knowledge, several states have sought legislation and regulations to mitigate workplace. ${ }^{[15]}$ The Healthy Workplace Bill (HWB) defines an abusive work environment, allows an employee to sue a bully, and compels employers to address toxic work environments. Since its first introduction to state law in California in 2003, the HWB was introduced in more than 25 states. ${ }^{[16]}$ State law currently requires employer run workplace violence programs in CA, CT, IL, MD, MN, NJ, OR, and NY. Workplace violence in this legislature is defined by NIOSH as "any physical assault, threatening behavior or verbal abuse occurring in the workplace. Violence includes overt and covert behaviors ranging in aggressiveness from verbal harassment to murder". ${ }^{[17]}$ The current state of forthcoming regulation and legislation movements, and the results of this study, suggest the organization consider systems to encourage a civil work culture which will also ease the transition into regulatory compliance.

\subsection{Limitations}

There are several limitations to consider in light of our findings. Response rate was $26 \%$ so findings may not represent all nurse workforce staff at the hospital. Results may have been impacted by the uneven breakdown of the employment type of the respondents, including a majority of military (65\%), 30\% GS and only 5\% contract employees. Findings were based on self-report of individual experiences in the work place and therefore potentially biased by differences in perceptions of what amounts to "uncivil" behavior. Future studies should consider using a standardized tool to measure and verify bullying behavior (e.g., through observation), as well as enhancing data collection strategies for a greater understanding of the phenomena in the MHS. Additional research that incorporates these elements may help organizations standardize their processes for identifying potential workplace incivility and more accurately tailoring interventions to address and regularly monitor workplace behavior. ${ }^{[3]}$

\section{Conclusion}

This study provided the nursing staff at a military hospital the opportunity to share perceptions of incivility and reflect on the impact of these experiences on the ability to provide quality healthcare to their patients. A better understanding of incivility in the military healthcare setting will inform interventions to mitigate the problem with goals such as improving employee communication and productivity, while reducing patient errors and ultimately enhancing military readiness. 


\section{ACKNOWLEDGEMENTS}

Thank you for the support and guidance of the following people who made this endeavor possible: COL Jeffrey Ashley and participating military hospital leadership and respon- dents.

\section{CONFlicts OF InTEREST Disclosure}

The authors declare that there is no conflict of interest.

\section{REFERENCES}

[1] WBI. Workplace Bullying Institute [Internet]. 2014. Available from: http://www. workplacebullying.org/

[2] Lutgen-Sandvik P, Tracy S, Alberts J. Burned by bullying in the American workplace: Prevalance, perception, degree and impact. Journal of Management Studies. 2007; 44(6): 837-862.

[3] Einarsen S, Hoel H, Notelaers G. Measuring exposure to bullying and harassment at work: Validity, factor structure and psychometric properties of the Negative Behaviors Questionnaire-Revised. Work \& Stress. 2009; 23(1): 24-44. http://dx.doi.org/10.1080/026 78370902815673

[4] The Joint Commission. Behaviors that undermine a culture of safety [Internet]. 2008. Available from: http://www. jointcommission. org/SentinelEvents/SentinelEventAlert/sea_40.htm

[5] The Joint Commission. Bullying has no place in health care. [Internet]. 2016. Available from: https://www. jointcommission.or g/assets/1/23/Quick_Safety_Issue_24_June_2016.pdf

[6] PACERS. Civility tool-kit. [Internet]. 2016. Available from: http: //stopbullyingtoolkit.org/

[7] ISMP. Intimidation: Practitioners speak up about this unresolved problem (part I). 2004. Available from: http: //www . ismp. org/N ewsletters/acutecare/articles/20040311_2.asp

[8] ISMP. Unresolved disrespectful behavior in healthcare; Practitioners speak up (again)-part I. ISMP Medication safety alert. 2013. Available from: http://www.ismp.org/Newsletters/acuteca $\mathrm{re} /$ showarticle . asp? id $=60$

[9] Mikkelsen E, Einarsen S. Bullying in Danish work work-life: Prevalence and health correlates. European Journal of Work and Organizational Psychology. 2001; 10(4): 393-413. http://dx.doi.org/1 $0.1080 / 13594320143000816$

[10] Osatuke K, Moore S, Ward C, et al. Civility, respect, engagement in the workforce (CREW): Nationwide organization development inter- vention at Veterans Health Administration. The Journal of Applied Behavioral Science. 2009; 45(3). http://dx. doi.org/10.1177 10021886309335067

[11] Farrell GA. Aggression in clinical settings: Nurses' views- a followup study. Journal of Advanced Nursing. 1999; 29(3): 532-541. http://dx.doi.org/10.1046/j.1365-2648.1999.00920.x

[12] Bartholomew K. Speak your truth: Process strategies for effective nurse-physician communication. Marblehead, MA: HCPro; 2010.

[13] Binney E. Experts recommend workplce bullying policies. HR Disciplines. 2012. Available from: http://www.shrm.org/hrd isciplines/employeerelations/articles/pages/expert s-recommend-workplace-bullying-policies .aspx

[14] OSHA. Workplace violence. [Internet]. 2015. Available from: http $\mathrm{s}$ ://www.osha.gov/SLTC/workplaceviolence/

[15] NIOSH. [Internet]. 2016. Available from: http://jama.jamanet work. com/article. aspx? articleid=2536076

[16] Healthy Workplace Bill. [Internet]. 2016. Available from: http: //healthyworkplacebill.org/bill/

[17] American Nurses Association. [Internet] 2016. Available from: http://www . nursingworld.org/MainMenuCategories/Po licy-Advocacy/State/Legislative-Agenda-Reports/Sta te-WorkplaceViolence

[18] Leekley L, Turnure S. The real healthcare reform. Durham, NC: In the Know, Inc, 2012.

[19] Dellasega C. When nurses hurt nurses: Recognizing and overcoming the cycle of nurse bullyng. Indianapolis, IN: Sigma Theta Tau International; 2011.

[20] Rittenmeyer L, Huffman D, Hopp L, et al. A comprehensive systematic review on the experience of lateral/horizontal violence in the profession of nursing. JBI Database of Systematic Reviews \& Implementation Reports. 2013; 11(11): 362-468. http://dx. doi . org/10.11124/jbisrir-2013-1017 